\title{
IS PATIENT SAFETY AT THE HEART OF MEDICAL EDUCATION IN INDONESIA? REFLECTION ON THE IMPACT OF THE NATIONAL EXAMINATION
}

\author{
Rachmadya Nur Hidayah ${ }^{1 *}$ \\ ${ }^{1}$ Department of Medical Education and Bioethics, Faculty of Medicine, Public Health, and Nursing, Universitas Gadjah Mada, \\ Yogyakarta - INDONESIA.
}

\begin{abstract}
Background: National examinations in Indonesia (UKMPPD) has been implemented since 2007 as a quality assurance method for medical graduates and medical schools. The impact of UKMPPD has been studied since then, where one of the consequences were related to how it affected medical education and curricula. This study explored the consequences of UKMPPD, focusing on how the students, teachers, and medical schools' leaders relate the examination with patient care. This study aimed to explore the impact of UKMPPD on medical education, which focusing on the issue of patient safety.

Methods: This study was part of a doctoral project, using a qualitative method with a modified grounded theory approach. The perspectives of multiple stakeholders on the impact of the UKMPPD were explored using interview and focus groups. Interviews were conducted with medical schools' representatives (vice deans/ programme directors), while focus groups were conducted with teachers and students. A sampling framework was used by considering the characteristics of Indonesian medical schools based on region, accreditation status, and ownership (public/ private). Data was analysed using open coding and thematic framework as part of the iterative process.

Results: The UKMPPD affected how the stakeholders viewed this high-stakes examination and the education delivered in their medical schools. One of the consequences revealed how stakeholders viewed the UKMPPD and its impact on patient care. Participants viewed the UKMPPD as a method of preparation for graduates' real clinical practice. The lack of reference for patient safety as the impact of the UKMPPD in this study showed that there were missing links in how stakeholders perceived the examination as part of quality assurance in health care.

Conclusion: The UKMPPD as a high-stakes examination has a powerful impact in changing educational policy and programmes in Indonesia. However, in Indonesia, the examination brought in the reflection on how the "patient" element was lacking from medical education. This research offers an insight on the concept of patient safety in Indonesia and how the stakeholders could approach the issue.
\end{abstract}

Keywords: UKMPPD, national licensing examination, impact, competence, patient safety, curriculum

\section{INTRODUCTION}

National examinations, either for the purpose of licensure or certification, are increasingly used around the world. In Indonesia, the national examination serves the purpose of certification (of competence) and exit examination for medical students at the end of their study. The examinationnamed as Uji Kompetensi Mahasiswa Program Profesi

*corresponding author, contact: r.nurhidayah@ugm.ac.id
Dokter (UKMPPD), has been implemented since 2007. This high-stakes assessment is considered one of the most impactful policy in medical education in Indonesia, driving changes in medical schools and other stakeholders involved in the system. However, little is known on how the examination affected the changes, including how stakeholders adapted and responded to the policy. 
Previous reports showed that the UKMPPD affected the learning process of students, ${ }^{1}$ the motivation of students, and the changes in curricula. These findings are in line with the findings in the US about the clinical skills curricula; where the USMLE Step 2 drove the development of clinical skills assessment in US medical schools, ${ }^{2,3}$ in Taiwan on the increasing use of clinical skills facilities in medical schools, ${ }^{4}$ and in South Korea on the changes in assessment of clinical skills. ${ }^{5}$ However, reflecting on how medical schools' achievements were vastly different across the AIPKI regions, this research tried to understand how the UKMPPD affected the medical schools, including their faculties and students. This research found intended and unintended consequences of the UKMPPD; exploring on the views of stakeholders on the purpose and the impact of the examination. However, this paper will focus more on the impact in relation with patient safety from stakeholders' point of view. Since the UKMPPD was established to ensure the quality of medical graduates in Indonesia (i.e., their competence in patient care); how the stakeholders perceived patient safety is a vital issue in this discourse.

\section{METHODS}

This study was part of a doctoral project, using a qualitative method with a modified grounded theory approach. The doctoral project explored the impact of the national examination (UKMPPD) on the education system in medical schools. The changes in medical schools-as consequences of the UKMPPD, were seen as a phenomenon and thus, were approached using qualitative methods to build a new knowledge. Even though this study viewed the impact of UKMPPD as an unknown phenomenon in Indonesian context, there have been several studies on the consequences of national licensing examinations in other countries. Therefore, the modified grounded theory approach was selected for this study.

\section{Ethical issues}

Ethical approval for the study protocol was granted from School of Medicine Research Ethics Committee, University of Leeds (Ref: SoMREC/14/087) and from Medicine and Health Research Ethics Committee, Faculty of Medicine, Gadjah Mada University (Ref: KE/FK/1134/ EC/2015). The approval letters were enclosed in research permit application letter and participant's invitation letters. Since this study was conducted after examinees/ students undertook UKMPPD, it was made clear to the participants that this study would not affect their examination results in any way.

\section{Sampling}

Purposive sampling selected 18 medical schools for the interview with medical schools' representatives; with 6 of those schools for focus groups with teachers and students. The sampling was conducted considering the regions, management types (public/ private), and accreditation level. The purposive sampling was conducted to represent each characteristic of medical schools in Indonesia; rather than proportionally sampling according to number of students or schools in Indonesia. This was based on the argument that each charactertistic may has its own challenges in running undergraduate medicine programme and implementing the national examination. The sampling framework is pictured in Figure 1. 


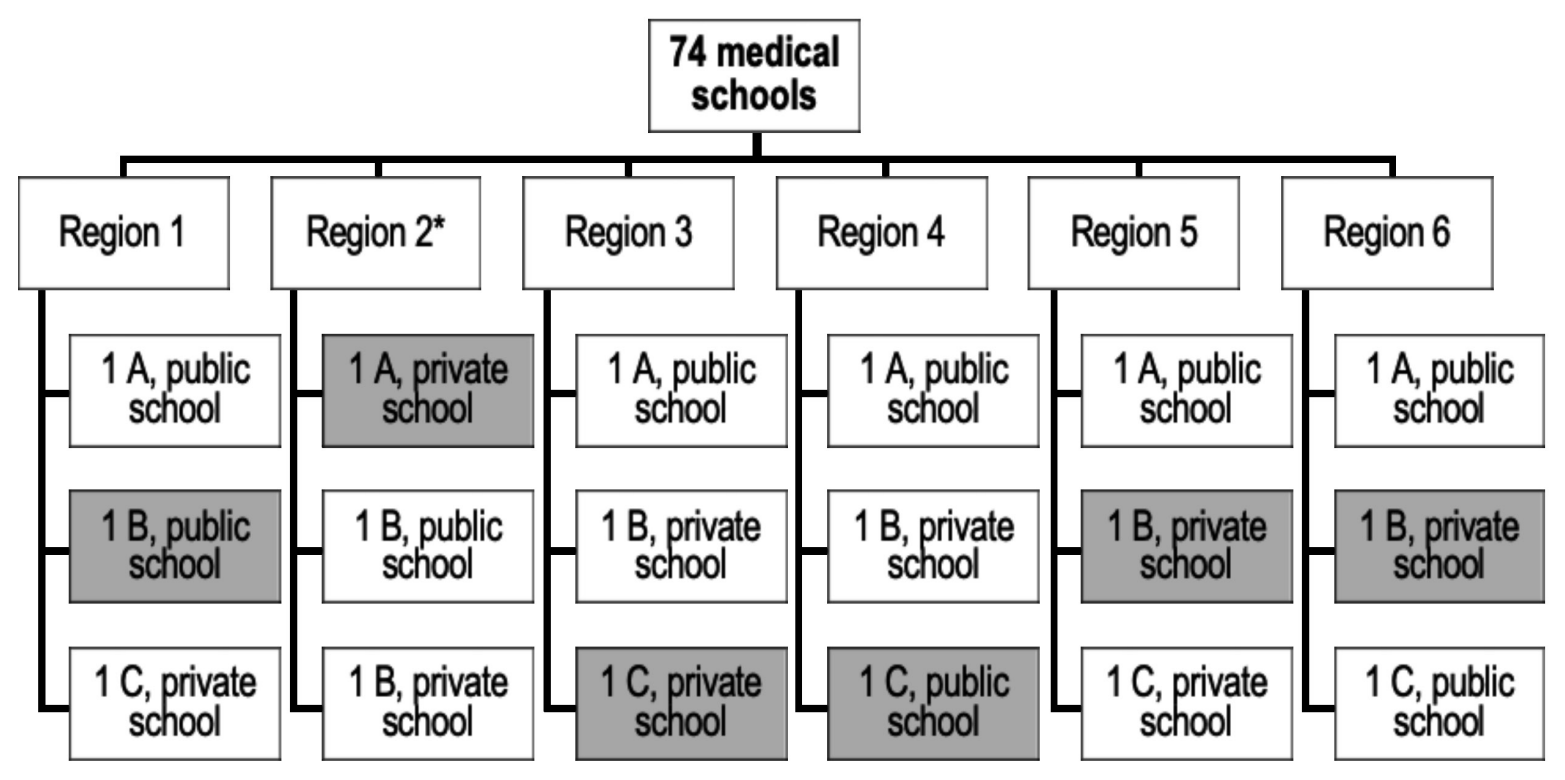

Figure 1. The sampling framework

Medical schools whose representatives were invited to be interviewed, were selected based on regions (1-6), accreditation level, and ownership (public/ private schools). There were 18 medical schools selected for the interview (all boxes). The shaded boxes represent selected medical schools for focus groups: 6 groups of teachers and 6 groups of teachers. Another inclusive criteria was the schools who had graduates undertaking the examination in November 2015. All six regions had A, B, and C-accredited schools, except region 2 which only had A and B-accredited schools.

\section{Data collection}

One-on-one interviews with 18 medical schools' representatives (Vice Deans/ Programme Directors) were conducted from December 2015 to March 2016. Focus groups with teachers and students were conducted in January-March 2016. Each group consists of 6-10 participants, with 48 students and 54 teachers in total. There were six focus groups with students and six focus groups with teachers. In one medical school, both focus groups were conducted on the same day at a different time and place. The interviews and focus groups were carried out in Indonesian language, using the Indonesian version of the guides. Interviews and focus groups were audio-recorded. Important quotes, issues/ themes, and nonverbal expression were written into notes. The audio files were transcribed into transcripts in the Indonesian language in written style transcripts.

\section{Data analysis}

The modified grounded theory approach used in this study determined how the data analysis was conducted. The data collection and analysis were conducted considering theoretical sensitivity as the key concept of the grounded theory. ${ }^{6}$ Initial open coding was conducted to generate concepts and themes. The initial concepts and themes were used to focus the next data collection and shaped the framework for thematic analysis. Thematic analysis was conducted by examining the themes and developing concepts into theories. In constructing concepts, convergence and divergence within and among groups of subjects were explored: comparing and contrasting between medical schools' representatives, teachers, and students' groups. Internal and external homogeneity and heterogeneity were identified to seek for better understanding of the phenomenon. ${ }^{7}$ This included the comparison between medical schools based on their characteristic (public and private schools, established and new schools, and accreditation status); which resulted in the cross-cutting themes. 


\section{RESULTS AND DISCUSSION}

The modified grounded theory approach enabled this research to explore the perspectives of the participants, which construct a new understanding on how the patient safety related to the high-stakes assessment and medical education in Indonesia. The findings will be into several themes below.

\section{The perspectives on the purpose of UKMPPD as a mean to ensure patient safety}

The UKMPPD as part of the quality assurance system to ensure high quality of care and consequently, supporting patient safety, is the purpose of the Government and regulators when they designed the policy. Most of the participants expressed agreement with this idea and how the UKMPPD could contribute to better health care professionals. However, some of them did not use the word/ term "patient" to refer to better care, but they most frequently used the term "better performance in practice". It is also worth noticing that the participants mostly expressed their opinions after prompting on how the UKMPPD affected the community and public.

"There must be [an impact]... If we expect them [the students] to be certified, of course we will have doctors who meet the standard. Public will have better health care, that is one of the purpose [of national examination]... If they failed the examination, they cannot do anything; [because] they are considered to be incompetent. They cannot get their licence for practice, registration certificate, etc ...." (VD-A)

"In health care, we must have certain standard to deliver care to patients. The national examination will give benefit for patients because the doctors meet the standard." (VD-K)

On the other hand, most teachers showed more concerns on how the UKMPPD serves as the mean to support health care improvement and public protection.
"As the decree said, by implementing this examination, we want to protect the public ..." $(\mathrm{T} 6-\mathrm{K})$

"We have to stand up for this regulation [of national examination as an exit exam], keep this standard ... If we don't, what will happen to the public or community?" (T4-I)

Only a few of them doubted the examination would affect patients: patients would not ask what were asked in test items.

"I think the OSCE is useful [to improve the quality of doctors] because that is the way we do the clinical practice... but for the CBT, let's say the pathomechanism questions, will our patients come with question such as "Doc, I feel this symptom, what is the pathomechanism?". That is impossible, right?" (T2-F)

Another argument -although a minority, for not taking the UKMPPD as a measurement of graduates' competence is that medical errors are inevitable. Errors and malpractice were perceived as more about 'accident', rather than incompetence and lack of professionalism.

"... [Students] have gone through clinical rotation, so if a case happens in real practice, we cannot blame the education; it is just an accident." (VD-G).

Despite the counter-arguments, students as examinees saw the UKMPPD as a significant mean to prepare themselves to enter clinical practice, rather than eliciting direct impact to patients. This point of view shows that students have different concern regarding the purpose of UKMPPD than their teachers and medical schools' representatives.

"I see UKMPPD as a tool to prepare myself as a doctor, before going into real practice ..." (S9-K)

"Of course, patients will get the benefit of it. They will be safer; there will be less malpractice 
... Because the doctors who serve them are the ones who meet the standard, who have the competence to perform their tasks..." (S1-F).

These findings show that there are discrepancies between medical schools' representatives, teachers, and students on how they perceive the UKMPPD in serving the purpose of patient safety. This finding resonates how they then perceive the UKMPPD affected the medical education and the graduate's competence in patient care.

\section{The undergraduate curricula and the importance of patient safety}

Analysing the impact of the UKMPPD resulted in the cross-cutting themes, found that in Indonesia, there was a high variety in interpreting the SKDI and translating it into the curricula. This study found that although the UKMPPD was designed to ensure the competence of medical graduates according to the SKDI, neither students nor teachers perceived that the patient safety component was clearly addressed in the UKMPPD. The frequently mentioned argument on this issue was that the SKDI was interpreted differently by medical schools; therefore, the formulation of curricula was varied between schools.

The different interpretation of SKDI -including how patients sit in the system, was expressed through how these stakeholders viewed the link between patients and their educational programme. The discourse of patient safety found in this study, was not directly linked with the UKMPPD and medical curricula. The term "patient safety" itself was not commonly mentioned by participants, which may indicate that the topic of patient safety was not an immediate part of both curricula and learning outcomes.

On the other hand, most of teachers and Deans focused on the "standardised" graduates and competence as their links to patients. Most of the representatives agreed that the education must produce competent, "standardized" graduates to deliver health care. "...doctors should be standardised because we are dealing with human. We cannot be careless for humanity ..." (PD-P)

"... I am talking from a user or patient's point of view. They deserve the right to be treated by standardised doctors, wherever it is, graduated from any schools. [This is why] every doctor has the same [procedure] to get a licence for practice ..." (VD-E)

\section{Cross-cutting theme: stakeholders' point of view on patient safety}

Stakeholders' view on the UKMPPD impact allowed this study to a deeper analysis resulting in a crosscutting theme; which formulate the understanding of patient safety in Indonesia. Patient safety was described as an expected impact of medical education output, which strongly related with standardised performance of graduates in clinical setting. Although this concept of patient safety related to the purpose of the UKMPPD; it stands as a detached and poorly defined concept. 'Patients' and 'clinical practice' seemed to be separated from undergraduate medical education. The insight on how medical errors and malpractice (which most likely results from the lack of patient safety competence) are perceived as an accidental event, showed that patient safety was not considered as an integral part of education. By referring it as a merely 'accident', despite the graduates have the standardised competence or not, it was assumed that they would eventually get into one.

Looking at the issue closer, the dissenting opinions coming from representatives, faculties, and students in this study, revealed that there was mismatch between the quality and the output of education. The connections between how the patient safety was not explicitly perceived as an output of medical curricula, with the existing assumptions that: 1) any assessment and learning process in all medical schools were already in a good quality, 2) the UKMPPD has less to do with patient care, 3) the errors and malpractice are less likely because of graduates' competence; indicates that the current education in some of Indonesian medical schools did 
not address the patient safety as a core competence to be learned. These assumptions by stakeholders may reflect the state of medical education in Indonesia, where education excellence is the focus and patients are not greatly involved nor embedded in education.

Exploring the consequences of the national examination in Indonesia opens the discourse of how medical schools' outcomes in relation with patient safety and to a further extent, the involvement of patient in medical curricula. Although the UKMPPD was designed to enforce a high quality of patient care -provided by competent medical doctors; this study found that some stakeholders were not aware nor consider patient benefit as the purpose of the examination. This brought the discussion to focus on several key issues.

\section{The national examination and impact on patients: Indonesia's views}

Among countries implementing the national examinations, almost all of them designed the examination to improve patient care. ${ }^{8}$ The concern of whether national examinations would give impact to patients, has been an ongoing debate for experts and educators. ${ }^{9} 10$ As Archer ${ }^{8}$ summarized in his review for the GMC, although until today there has been limited evidence of licensing examination on patient safety, there were studies showing that there were consequences for better patient care in relation with the licensing examination. Since there are confounding factors affecting patient care, the research of evidence of national licensing examination's (NLE's) impact on patient has been focusing on some indicators. Tamblyn ${ }^{11}$ highlighted the correlation of good performance in the USMLE with lower number of patient's complaints; while Norcini ${ }^{12}$ found that better performance in the USMLE resulted in better performance in clinical care. Other research show that NLE's scores have a predictive value for future performance in practice. ${ }^{13,14}$

Although this study did not focus on the impact of UKMPPD on patients, it explored the views of graduates, faculties, and medical schools on how the examination may affect patients in Indonesia.
Compared to other studies exploring the impact of national examinations, it is worth noting that in this study, most participants preferred to mention components of patient safety rather than stating that improved patient care as the main purpose of the UKMPPD. The components of patient safety identified as the expected outcomes of UKMPPD are competent doctors, knowledge of professional tasks, and preparedness for practice. Participants mostly understood that there were 'unexpected' factors in clinical practice, e.g., uncertainty and medical errors, which may be a confounding factor to measure the impact of UKMPPD.

\section{How patient safety is placed in Indonesia's medical curricula}

Swanson and Roberts ${ }^{15}$ proposed that NLEs major contribution is providing public (including patients and employers) reassurance of the quality of doctors regardless of their medical schools, region and curricula. The findings of the bigger part of this study ${ }^{16}$ confirmed changes in education, e.g., curricula, assessment, evaluation, and faculty development. Since the concern of patient safety arise from this study, there should be more attention to the discourse on where the curricula of medical professions stand in issue.

Patient safety is clearly stated in the standard of competence for Indonesian Medical Doctors (SKDI - Standard Kompetensi Dokter Indonesia), as one of the purposes of the medical education in Indonesia. The regulators of medical practice (i.e., the Ministry of Health and the Indonesian Medical Council) emphasised, in the guidelines for clinical practice, that patient safety and patient centeredness are the focus of good clinical practice. What the findings of this study revealed is that the 'end product' of the medical education process seemed to have been forgotten, where medical educators and students did not think as far as the impact on patient. This lack of awareness could be derived from how the competencies of patient safety in the SKDI were embedded in the curricula and translated into learning activities and assessment. This proposed another challenge for medical schools and the regulator: how to put the concept of patient safety 
at the heart of medical education, while recognising the local context of Indonesia.

The inclusion of patient safety in undergraduate medical curricula, either as a stand-alone course or embedded programme, is still limited. ${ }^{17}$ The WHO published Patient Safety Curriculum Guide for medical schools to provide guideline for curriculum development and delivery, which aimed for improvement in health care. ${ }^{18}$ There have been several studies looking at how to design and deliver the patient safety in medical curricula, which could be considered by stakeholders in Indonesia. Sandars et al. ${ }^{19}$ proposed important areas to prioritize in the curricula, while considering for local/ regional needs. Other works in this area showed the benefit of longitudinal programme, ${ }^{20}$ continuous development throughout the transition from undergraduate to postgraduate phase, ${ }^{21}$ and the interprofessional education, ${ }^{22,23}$ for the learning of patient safety in undergraduate programme. The curricula should focus on the role of students in preventing harm and enhancing patient safety, ${ }^{24}$ raising awareness of the issue, for the graduates as future doctors delivering better health care for patients. ${ }^{25,26}$ It is now the opportunity for policy makers and medical schools as stakeholders to address the challenge of patient safety and education, not only for medical but also for other health care professions.

\section{CONCLUSION}

The core competence regarding patient safety need to be made clear and patient should be involved in education. Even though this study did not focus on patient safety, it offers an insight into how to view the issue and its challenges in Indonesia. The issue of patient safety in medical education needs collaborative effort from all stakeholders, and it offers the chance to develop contextual and integrated patient safety curricula to support the high-quality medical graduates as the output of education. In the near future, there should be an evaluation of how medical schools deliver patient safety competence in their curricula which could raise awareness of both students and teachers on the importance of the competence.

\section{DECLARATION OF INTEREST}

The author declares that there is no conflict interest presented in the manuscript.

\section{ACKNOWLEDGEMENT}

This study was part of a doctoral project funded by the Indonesia Endowment Fund for Education (LPDP - Lembaga Pengelola Dana Pendidikan).

\section{REFERENCES}

1. Firmansyah M, Widyandana W, Rahayu GR. Studi Kualitatif Dampak Uji Kompetensi Dokter Indonesia terhadap Pembelajaran pada Mahasiswa Kedokteran. Jurnal Pendidikan Kedokteran Indonesia: The Indonesian Journal of Medical Education. 2015;4(3):129-39.

2. Hauer KE, Teherani A, Kerr KM, O'Sullivan PS, Irby DM. Impact of the United States Medical Licensing Examination Step 2 Clinical Skills exam on medical school clinical skills assessment. Academic Medicine. 2006 Oct 1;81(10):S13-6.

3. Gilliland WR, Rochelle JL, Hawkins R, Dillon GF, Mechaber AJ, Dyrbye L, Papp KK, Durning SJ. Changes in clinical skills education resulting from the introduction of the USMLE ${ }^{\mathrm{TM}}$ step 2 clinical skills (CS) examination. Medical teacher. 2008 Jan 1;30(3):325-7.

4. Lin CW, Tsai TC, Sun CK, Chen DF, Liu KM. Power of the policy: how the announcement of high-stakes clinical examination altered OSCE implementation at institutional level. BMC medical education. 2013 Dec;13(1):8.

5. Park HK. The impact of introducing the Korean Medical Licensing Examination clinical skills assessment on medical education. Journal of the Korean Medical Association/Taehan Uisa Hyophoe Chi. 2012 Feb 1;55(2).

6. Corbin J, Strauss A, Strauss AL. Basics of qualitative research. Sage; 2015.

7. Cohen L, Manion L, Morrison K. Research methods in education. Routledge; 2018.

8. Archer J, Lynn N, Coombes L, Roberts M, Gale T, Price T, de Bere SR. The impact of large scale licensing examinations in highly developed countries: a systematic review. BMC medical education. 2016 Dec;16(1):212.

9. Archer J, Lynn N, Coombes L, Roberts M, Gale T, Regan de Bere S. The medical licensing 
examination debate. Regulation \& Governance. 2017 Sep;11(3):315-22.

10. Harden RM. Five myths and the case against a European or national licensing examination. Medical Teacher. 2009 Jan 1;31(3):217-20.

11. Tamblyn R, Abrahamowicz M, Dauphinee D, Wenghofer E, Jacques A, Klass D, Smee S, Blackmore D, Winslade N, Girard N, Du Berger R. Physician scores on a national clinical skills examination as predictors of complaints to medical regulatory authorities. Jama. 2007 Sep 5;298(9):993-1001.

12. Norcini JJ, Boulet JR, Opalek A, Dauphinee WD. The relationship between licensing examination performance and the outcomes of care by international medical school graduates. Academic Medicine. 2014 Aug 1;89(8):1157-62.

13. Tamblyn R, Abrahamowicz M, Dauphinee WD, Hanley JA, Norcini J, Girard N, Grand'Maison P, Brailovsky C. Association between licensure examination scores and practice in primary care. Jama. 2002 Dec 18;288(23):3019-26.

14. Wenghofer E, Klass D, Abrahamowicz M, Dauphinee D, Jacques A, Smee S, Blackmore D, Winslade N, Reidel K, Bartman I, Tamblyn R. Doctor scores on national qualifying examinations predict quality of care in future practice. Medical education. 2009 Dec;43(12):1166-73.

15. Swanson DB, Roberts TE. Trends in national licensing examinations in medicine. Medical education. 2016 Jan;50(1):101-14.

16. Hidayah RN. Impact of the national medical licensing examination in Indonesia: perspectives from students, teachers, and medical schools (Doctoral dissertation, University of Leeds). 2018.

17. Nie Y, Li L, Duan Y, Chen P, Barraclough BH, Zhang M, Li J. Patient safety education for undergraduate medical students: a systematic review. BMC medical education. $2011 \mathrm{Dec} ; 11(1): 33$.

18. Walton M, Woodward H, Van Staalduinen S, Lemer C, Greaves F, Noble D, Ellis B, Donaldson L, Barraclough B. The WHO patient safety curriculum guide for medical schools. BMJ Quality \& Safety. 2010 Dec 1;19(6):542-6.
19. Sandars J, Bax N, Mayer D, Wass VA, Vickers R. Educating undergraduate medical students about patient safety: priority areas for curriculum development. Medical teacher. 2007 Jan 1;29(1):60-1.

20. Patey R, Flin R, Cuthbertson BH, MacDonald L, Mearns K, Cleland J, Williams D. Patient safety: helping medical students understand error in healthcare. BMJ Quality \& Safety. 2007 Aug 1;16(4):256-9.

21. de Feijter JM, de Grave WS, Dornan T, Koopmans RP, Scherpbier AJ. Students' perceptions of patient safety during the transition from undergraduate to postgraduate training: an activity theory analysis. Advances in health sciences education. 2011 Aug 1;16(3):347-58.

22. Tregunno D, Ginsburg L, Clarke B, Norton P. Integrating patient safety into health professionals' curricula: a qualitative study of medical, nursing and pharmacy faculty perspectives. BMJ Qual Saf. 2014 Mar 1;23(3):257-64.

23. Kyrkjeb $\varnothing$ JM, Bratteb $\varnothing$ G, Smith-Strøm H. Improving patient safety by using interprofessional simulation training in health professional education. Journal of interprofessional care. 2006 Jan 1;20(5):507-16.

24. Seiden SC, Galvan C, Lamm R. Role of medical students in preventing patient harm and enhancing patient safety. BMJ Quality \& Safety. 2006 Aug 1;15(4):272-6.

25. Thompson DA, Cowan J, Holzmueller C, Wu AW, Bass E, Pronovost P. Planning and implementing a systems-based patient safety curriculum in medical education. American Journal of Medical Quality. 2008 Jul;23(4):271-8.

26. Myung SJ, Shin JS, Kim JH, Roh H, Kim Y, Kim J, Lee SI, Lee JH, Kim SW. The patient safety curriculum for undergraduate medical students as a first step toward improving patient safety. Journal of surgical education. 2012 Sep 1;69(5):659-64. 